\title{
FinTech as an innovation challenge: from big data to sustainable development
}

\author{
Anzhela Ignatyuk, Olena Liubkina, Tetiana Murovana*, and Alina Magomedova \\ Taras Shevchenko National University of Kyiv, Faculty of Economics, 90-A Vasylkivska Str., 02090, Ukraine
}

\begin{abstract}
Driving force of human society development is elimination contradiction between unlimited usage of natural resources during economic activity of enterprises, environment pollution as a result of such activity and limited natural, energy and other resources. Research results on economic and environmental issues of green business management showed that there are several basic types of problems at present which arise at enterprises during collecting and processing data on the results of their activities. The authors analyzed how public sector and green business is catching up on global trend towards broader use of the big data analysis to serve public interests and increase efficiency of business activities. In order to detect current approach to big data analysis in public and private sectors authors conduct interviews with stakeholders. The paper concludes with the analysis what changes in approaches to the big data analysis in public and private sectors have to be made in order to comply with the global trends in greening the economy. Application of FinTech, methods of processing large data sets and tools for implementing the principles of greening the economy will enable to increase the investment attractiveness of green business and will simplify the interaction between the state and enterprises.
\end{abstract}

\section{Introduction}

In modern conditions of socio-economic development, leadership in the world markets belongs to the countries whose economic development is dominated by innovation activity. There is always a demand for green innovations, so they are and should be a priority in the policy of any country that is constantly striving for economic development. In most developed countries, the regulation of innovation activity takes place through different levels of government participation. At that, the key role in the processes of innovation activity is given to the subjects of entrepreneurship (transnational corporations, representatives of large, medium and small businesses).

At present, it is possible to highlight the main directions of stimulation of innovative activity of developed countries: implementation of large and perspective target projects in sustainable development that cover all stages of the scientific and production cycle, usually with a significant part of scientific and innovative potential, creation of a favourable innovation environment, development of green innovations through the development of innovation infrastructure, sensitive to the achievements of world scientific and technological progress, coordination and interaction of various economic sectors in the field of science, environment and technology, distribution of green innovations.

Governments worldwide accumulate wide range of datasets containing information about different processes involving many actors. Recently it has become evident that new instruments of big data analysis could put unstructured datasets to use. Possibilities to use large datasets are considered in both private and public sector. Private businesses use big data to increase profits whereas government is interested in more efficient policymaking and realization of sustainable development principles.

Incorporating fragmented datasets collected by different agencies especially when they become available to the public facilitate achievement of goals of the public sector, private sector and civil society. On the other hand there are many factors that limit feasibility of substantial increase in utilization of big data analysis in decisionmaking process in nearest future: high cost of technical solutions, fragmentation of datasets and complexity of data-sharing between different agencies, lack of expertise in big data analysis among public servants, low level of data security etc.

\section{Research results}

\subsection{Sustainable development trends and challenges}

Investment into natural environment protection is an important component of state ecological and economic policy in countries around the world. According to research of International Organization REN 21 [1, 2], amount of green investments in 2004 was 47.0 billion dollars and by the end of 2015 it was 312.2 billion dollars that is 6 times more than in 2004. Then there was a slight reduction of investments into renewable sources, however

\footnotetext{
Corresponding author: murovana.tetiana@gmail.com
} 
by the end of 2017 the amount increased and reached 241.6 billion dollars.

Slight reduction of green investment, first of all, caused by cutting down financing of alternative sources projects development (solar power, thermal and hydropower, biofuels), switching and using more such traditional sources as nuclear energy. Projects on improving energy efficiency for existing technologies and installations become more popular.

The largest volume of green investments directed into implementation measures of environment protection accrue to (Fig. 1): China $-78,3$ billion dollars, United
States of America - 46,4 billion dollars, Great Britain 24,0 billion dollars, Japan $-14,4$ billion dollars, Germany $-13,2$ billion dollars, India $-9,7$ billion dollars, Brasilia $-6,8$ billion dollars, Australia $-3,3$ billion dollars, Belgium $-2,9$ billion dollars, France $-2,6$ billion dollars. Instruments of green economy are used in these countries not only at level of state regulations in terms of developing green strategies and measures for its implementation but also at level of enterprises during formation of environmental management systems and management decision making.

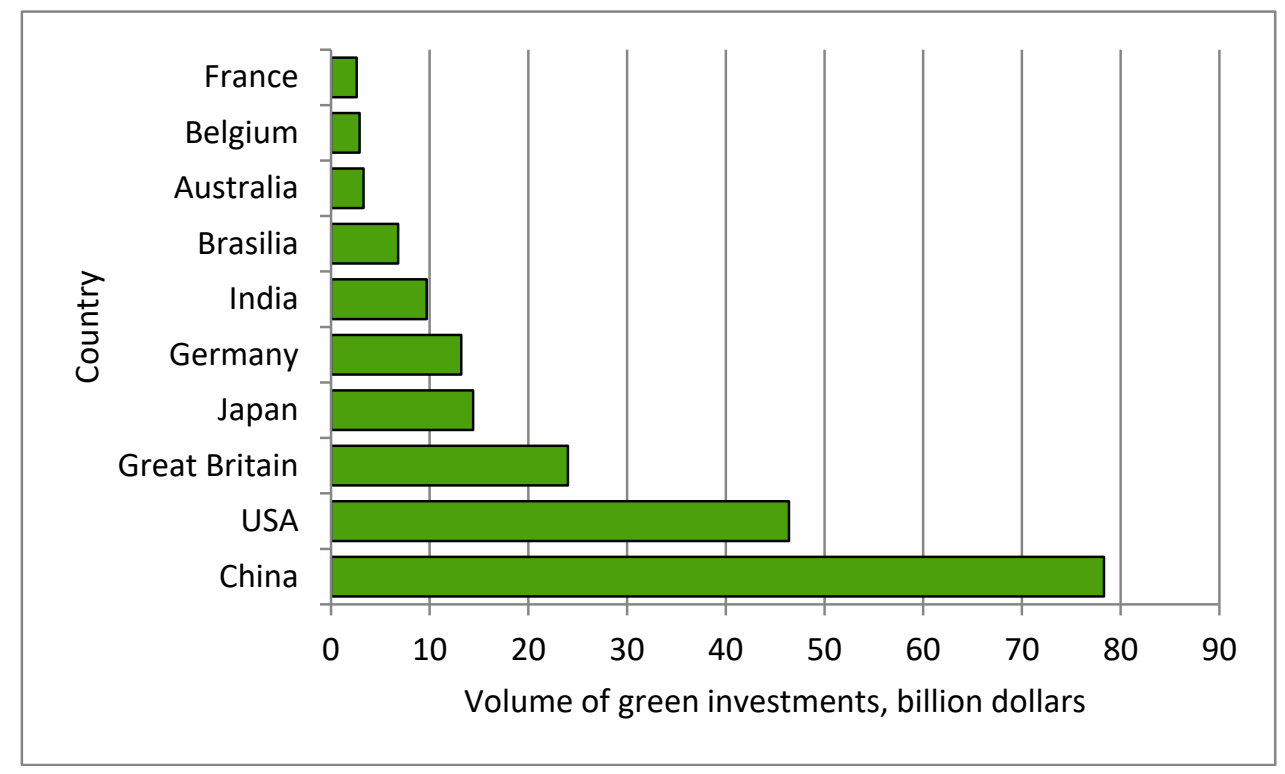

Fig. 1. Green investments directed into implementation measures of environment protection in 2017.

At present, green energy sources come up to $19 \%$ of global electricity consumption. The largest producers of green energy sources were such countries as: China, USA, Great Britain, Japan and Germany. Despite a number of problems related to reduction support of development of the sector at legislative level and deterioration in the business environment in many countries in the world, the sector of economy continues developing. Significant development is observed at energy industry where the amount of produced energy resources increased more than $8 \%$. Sales in hydropower sector increased by $4 \%$, other renewable resources - almost by $17 \%$. Along with other renewables sales of solar and wind power declined. The reason is that it is more expensive way to produce electricity compared to alternative energy sources; first of all it is connected to weather conditions and production downtime. Therefore, a large number of wind and solar power construction projects remain without government financial support.

Unlike previous types of alternative energy sources, usage of biofuels increased significantly. It is related to both gaseous biofuels (mainly biogas) and development of hybrid versions as biodiesel - natural gas for busses and electric diesel vehicles. Using biofuels is highly profitable in many countries in the world because these resources are renewable in comparison to natural resources (oil, gas, coal etc.). Besides, increasing demand for biofuel leads to expanding of renewable sources market and provides creating additional workplaces.

Renewable energy is one of the most promising types of economic activity in a green economy. For many years hydropower has been predominant among the world's renewable energy production units, producing more than $50 \%$ of the total production capacity. In 2017, hydropower production was $1096.0 \mathrm{GW}$, or $54.36 \%$. Among other types of green energy the leading place is given to the following types: wind energy $-487.0 \mathrm{GW}$ or $24.2 \%$, solar energy produced by photovoltaic methods $303.0 \mathrm{GW}$ or $15.0 \%$, bioenergy $-112.0 \mathrm{GW}$ or $5.6 \%$, geothermal energy $-13.5 \mathrm{GW}$ or $0.7 \%$, solar energy produced by concentrating type systems $-4.8 \mathrm{GW}$ or $0.2 \%$ (Fig. 2).

Over the past ten years, the economic sector has grown enormously. In fact, about $80.0 \%$ of natural resources were used to produce electricity. Despite that fact that investments into projects for production of solar cell batteries were reduced, modernization of the sector was done; thereby, power of such batteries was increased by $32 \%$. Such renewable energy sources as solar energy, wind and heat are used widely. For example, EU countries switch to using wind energy more and more. In Denmark the figure is $33.2 \%$ of total produced electricity, in Spain $20.9 \%$. At the same time, Italy reduced consumption of other types of energy by $7.8 \%$ due to solar energy. 
Governments and representatives of green businesses are increasingly using FinTech and big data analysis to serve public interests and increase efficiency of business activities. The use of modern methods of data processing and analysis allows predicting trends in the development of the world economy, the situation on international markets, to determine the directions of economic and environmental policies of different countries, and for green businesses not to lose profitability and increase the efficiency of activity.

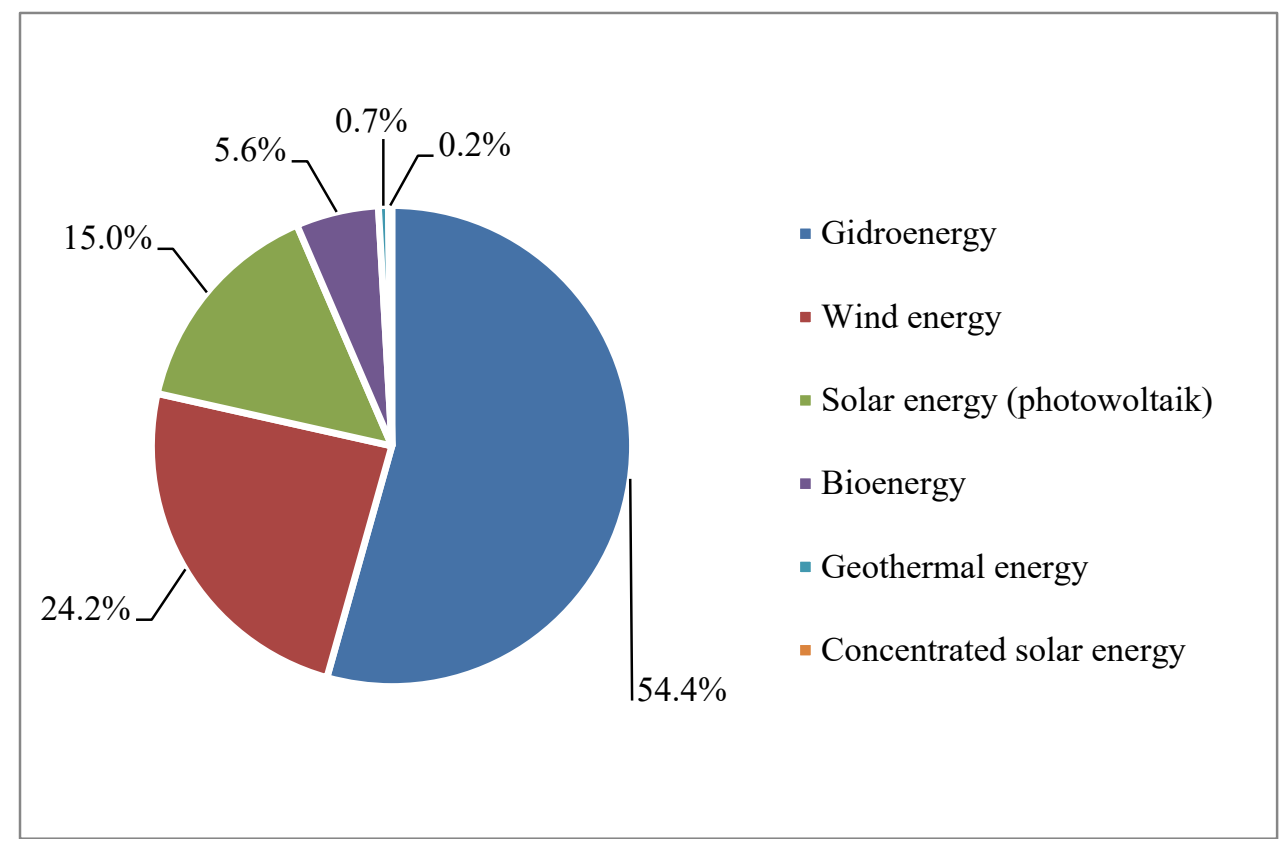

Fig. 2. Structure of renewable energy sources in 2017 , $\%$.

\subsection{Big data role in FinTech development}

The financial support system for innovation activity in the field of green business is derived from geopolitical, sociopolitical and macroeconomic processes. The overall cost of innovation can include the enterprise's costs to innovate something new in the field of green technologies both to the enterprise and to the market, including internal research, acquisition of $\mathrm{R} \& \mathrm{D}$ products, machinery, equipment and software, any external knowledge, and other expenses.

The only problem with the use of financial technologies in the field of green business is that market mechanisms are not able to attract investment in green projects. This is due to the high riskiness of the projects and the long payback period. Therefore, government support plays a big role in green business. In such circumstances, FinTech and their instruments play a significant role in attracting green investments as they are able to justify their economic and social effectiveness.

Digitalization increasingly influences both public institutions and green business entities. FinTech will eventually become essential in decision-making process in both public and private sector, even though FinTech initiatives and infrastructure develop more rapidly in private sector. Ability to use big data analysis as a tool of FinTech development is an important competitive advantage in modern green markets.

Regression analysis can be one of tools for the green investment analysis. The following model (1), developed by I. Rakov [8] on the basis of research by H. Akaike [9] and G. Schwarz [10], allows evaluating the effectiveness of state support in attracting investments in the field of green business:

$$
y_{t}=\alpha+\beta_{1}\left(L^{i}\right) x_{1, t}+\beta_{2}\left(L^{j}\right) x_{2, t}+\beta_{3}\left(L^{p}\right) x_{3, t}+\varepsilon_{t}
$$

The dependent variable $y_{t}$ is the amount of green investment per year. The independent variable $x_{1, t}$ is an amount of government spending on environmental protection and the independent variable $x_{2, t}$ is an indicator of the effectiveness of the state's environmental policy. World GDP is an external factor $x_{3, t}$ which is effects on the country's economic development and investment attractiveness. The time lags $L^{i}, L^{j}, L^{p}$ are estimated to be one year and $\varepsilon_{t}$ is an error term [8].

Such a model is appropriate in economic, environmental and social terms and deserves attention. As can be seen from this model, it requires analysis of a large number of macroeconomic indicators, and this is only possible with the use of big data analysis and the involvement of FinTech.

Boyd and Crawford [3] underline complicated process of analyzing big data as its distinctive characteristics. Big data is related to business intelligence and market analytics. Developing tools for making effective decisions based on analyzing big data on green business activity is becoming an increasingly important issue for practice. Data becomes cheaper and more accessible, but analysis makes it important and valuable in decision making. The emergence of e-documenting initiatives and enterprise environmental reporting is closely linked to the challenges of new approaches to big data analysis in the public sector and the private sector involved in green business. 
Crawford [4] draws attention to existence of the potential of biased approach towards big data analysis depending on agenda. Quantitative analysis can be refining with qualitative research, but in this case more sophisticated methods have to be used. Public Sector institutions generate, collect and store many different datasets that are effectively big data, but in majority of cases green business decision-making process does not involve big-data analysis. Limits and potential of the big data analysis are defined by the existing ways of collecting and storage of the datasets, existing infrastructure, and experience in green entrepreneurship, alternative energy, green production, and more.

As noted by K. Desouza and B. Jacob [5] big data initiatives have emerged on different levels of the governments of the advanced economies. Big data on green economy development can be distinguished from ordinary data by four main factors: volume, speed, variety and complexity. Big data is a big data set on green market development, sales volume, new market players, built quickly. Particularly important is the fact that such data is composed of different elements and is largely unstructured.

G. Kim, S. Trimi and J. Chung [6] provide comparison of the private and public sector in terms of potential usefulness of analysis of the big data, the main goals (profit-making for green business entities and public goods provision for the public sector) as well as timeframe of the impact (short-term for green business entities and long-term (strategic) for public sector).

J. Mervis [7] emphasizes substantial efforts that governmental agencies put into improving ability to utilize big data in process of implementation of the green strategy. Governments of the developing countries are following global trend in sustainability and explore potential options to use big data analysis in public sector in order to increase efficiency of the decision-making process. Lack of tools to quantify the efficiency of public spending on the big data analysis is one of the problems faced by the governments that can limit financing of the projects in the field of greening.

In practice, FinTech is a startup project that implements modern financial technologies and makes financial services more efficient. However, the cost of implementing and servicing such projects is reduced. The implementation of such projects entails a reduction in the banks' aggregate profits, overdraft revenues and the cost of payment services. At the same time, the increased risk of liquidity loss increases as the customer becomes less dependent on a particular banking institution. In this context, the problem of effective management of the financial sector and implementation of effective policy by the national bank of the country is becoming increasingly important.

The policies of financial institutions at the state and regional levels should be aimed at investing in Fintech start-ups. They help banks reduce costs and provide customers with new services. The rapid development of the Ukrainian Fintech has been caused by the unstable economic situation in the country in the last 10 years. As a result, public access to banking services has decreased significantly and distrust of traditional financial institutions has increased.

As a result, many national initiatives were launched by the National Bank of Ukraine aimed at supporting the Fintech industry, including: adopting Ukraine's digital strategy, switching to digital circulation, authorizing the use of electrode signatures, implementing universal Bank ID and Mobile IDs.

The main purpose of Ukrainian Fintech today is money transfers and crediting. Other participants work in the fields of financial management, infrastructure, marketplaces, telecommunications, blockchain, media and others. Among the most relevant services are: alternative payment methods (payment terminals, contactless and mobile payments, QR payments, electronic and digital wallets), mobile phone services, financial services and social networking services, marketplaces, artificial intelligence, open APIs, digital and biometrics identification etc.

\subsection{Big data for the public and private sectors in Ukraine}

Rapid technological and social changes lead to dynamic changes in the economic environment and the loss of investment attractiveness of old business models, including in the financial sector. Investments in green models and projects are becoming increasingly relevant. Against this background, the strengthening of the financial stability of the banking system and its greening are becoming increasingly relevant and important.

The National Bank strives for financial sector regulation to stimulate economic development on a sustainable basis, taking into account environmental challenges and the needs of all actors involved. The National Bank's strategy identifies a number of managed activity priorities. The main instruments include: achieving low and stable inflation, ensuring the stability of the banking system, resuming lending and currency liberalization, adaptive regulation of the financial sector. Creating conditions for the development of new green Increasingly relevant is the creation of conditions for the development of new green financial instruments and business models that meet the requirements of international standards, alignment of national regulatory framework with international standards and EU legislation, transformation of the National Bank and greening the financial system as a whole. In this context, the use of running dates to respond quickly to rapid economic changes and justify the feasibility of environmental projects is becoming increasingly relevant.

Public sector agencies in Ukraine tend to collect data about their counterparts from the private sector every time it is possible, large portion of the data collected by them exists in paper format and cannot be reached by other public sector institutions. Datasets collected by public sector institutions in digital format are mainly unstructured and stored in separately in information systems of each agency. Thus, when private sector actors in Ukraine encounter different public sector agency, they 
have to provide them with relevant data, even if these datasets have already been delivered to the other agency.

The green economy sector is no exception to these situations. The issue of securing personal data collected by different public sector agencies remains problematic, since IT-infrastructure is obsolete and lack of financial resources leads to fundamental fragility of the system.

Approaches to analysis of the big data in public sector in Ukraine use Estonian experience as a blueprint. Ukrainian IT-system for e-government "Trembita" (implemented in Ukraine since 2018) is an adaptation of the X-Road system. The main value of implementing "Trembita" in Ukraine is that all public sector bodies will have an opportunity to share data in real time. In case of successful implementation of the system, there will be no need to collect overlapping datasets and store it in databases.

Nowadays each public sector agency collects as much information about business as possible. This system is a key to reengineering of administering processes in the public sector, it will be the main tool for implementation of reforming variety of spheres, especially in the sphere of ecologization of enterprise activity. Interaction between governmental bodies, between public and private sector bodies are inefficient, heavily bureaucratized, resource-intensive. IT-based solutions in public sector will increase quality of processes in public and private sectors.

Open data (datasets available for free use and sharing) initiatives in public sector in Ukraine are implemented under "National anti-corruption strategy", realization of the policies in open data sphere is carried out by the State agency of electronic governance of Ukraine. The unified web-portal data.gov.ua provides open data from different actors of the public sector of Ukraine. The State agency of the electronic governance develops and implements strategic documents, recommendations concerning open data in public sector, ensures improvement of quality of datasets and their use. The Cabinet of Ministers of Ukraine defined the datasets that are obligatory to publish on data.gov.ua portal, these datasets are available for machine reading and subsequent analysis by public and private sector actors. The number of open data datasets published by public sector institutions in Ukraine is expected to reach 50000 by 2020 and government included stimulating development of projects based on open data analysis as one of priorities in it plan of actions until 2020.

Development of the big data analysis in public sector in Ukraine is within framework of implementing electronic democracy. Particularly important for big data analysis is creation of public-private partnership projects (mainly based on Open Data analysis). Green business in Ukraine needs a lot of support from the state, so creating a public-private partnership in this area is essential and important.

According to the Ukraine-EU association agreement, Ukrainian legislation has to be harmonized with "the highest European and international standards" in personal data protection. Thus, the Action Plan on implementation of the Ukraine-EU Association agreement contains implementation of GDPR (enacted in the EU on 25th of
May 2018) that contains important regulations concerning modes of use of personal data.

For now, Ukraine is considered country with low level of safety of personal data, but implementation of GDPR in Ukrainian legislation is pending for now. According to information shared by those involved in preparation, the main features of GDPR will be implemented in Ukraine: consent to process personal data will be in more understandable format, possibility to withdraw previously given consent to process personal data will be guaranteed, users of personal data will be obliged to implement reliable mechanisms to secure personal data, - these changes will make Ukrainian legislation similar to the EU regulations.

Data governance and privacy concerns arise in connection with big data analysis in public and private sectors, since it is important to ensure secure storage of personal data and prevent illegal use of the datasets.

\subsection{Big data analysis in financial sector}

In order to identify what approaches towards big data analysis can be the most beneficial for sustainability and greening the economy of Ukraine we relied on information acquired from interviews with representatives of the National Bank of Ukraine. This public sector institution was chosen as an object of investigation of possible approach towards big data analysis in public sector in Ukraine because of several reasons. It is perceived by experts as one of the most modernized and independent institutions of the public sector in Ukraine, it has proven track record of capability to perform successful reforms of its internal processes and transfer of the experience both to other public sector institutions and commercial banks. The National Bank of Ukraine is responsible for the large part of drafting the strategy of economic development.

Central banks in many countries increasingly use big data to improve efficiency and strengthen supervisory functions in banking system, compliance assessment, macroeconomic analysis, increase relevance of decisions concerning monetary policy, green development, regulate transactions between different green business actors, carry out stress-testing at the enterprises.

The international practice of big data application in central banks worldwide was reviewed. Thus, a division with functions of methodological support of big data analysis was established. This division is expected to develop tools for inclusion of high-frequency alternative macroeconomic indicators, media indicators and elements of machine learning in process of data analysis.

Traditional approach towards data analysis in National Bank of Ukraine include collection of relatively small amounts of highly structured data acquired from historically reliable sources, coherent and clear model of data analysis is employed. On the other hand, data is entered and processed manually and it is quite timeconsuming process, only official data is taken into consideration (which is a significant drawback in Ukraine, since shadow economy constitutes more than $35 \%$ of the economy). 
At first it was important to make sense of the term "Big Data" as large datasets from traditional sources, but later it became evident that sources of the big data are broader. Thus, the need to broaden range of data available to refine results of the analysis of green sectors and green economy development have led the National Bank of Ukraine to explore possibilities to include big data analysis in decision making and economic analysis process.

Motivation to implement big data in the National Bank of Ukraine is in large part connected to the need to adopt more forward-looking approach towards economic analysis and prudential regulation, more efficient fraud prevention, combat corruption, improve compliance analysis, develop monetary policy. In order to draft a plan to implement big data analysis in National Bank of Ukraine the experience of central banks of the EU, Thailand, Indonesia, China, Japan, UK, India were compared in order to identify the areas of potential use of the big data.

Representatives of the National Bank of Ukraine perceive big data analysis as a tool to optimize processes of data collection (shift from manual and time-consuming processes to automated real-time monitoring, reporting and consolidated data collection), it is expected that specialized modern software will facilitate machine learning and supthech (supervisory technology) development. Quality of the standard data can be improved if unconventional sources of big data are included to refine datasets such as: web-sources, APIsources, social media etc.

The National Bank of Ukraine is already conducting web-scraping of some alternative macroeconomic indicators (such as index of sustainable development, international innovation index, consumer price index, unemployment rate etc.), uses application programming interface (API) to formulate alternative macro indicators. Training for employees to study Python programming language was carried out in order to have in-house competencies in web-scraping. It is planned to further develop competencies of the staff of the NBU in the field of big data analysis and work with both public and private sector actors to share datasets. The NBU has a plan to build modern big data analysis infrastructure until 2020 to be able to use web-search, social media, API, blockchain technology. In case existing initiatives in big data analysis in the NBU are implemented, it is expected that financial supervision will improve, monetary policy will be more relevant and decision-making process will become faster, cheaper and more efficient.

\subsection{Modernization of economy on the basics of green growth}

There is a demand to develop effective measures for ecologization under current complex economic and ecological conditions. It becomes possible by creating global model of green business development which is based on investments of state funds in profitable environmental projects and conservation of natural resources for future generations. Priority measures for economy ecologization should consists of: assessment of the natural services providing at international, national and regional levels; effective environmental policy; use of market mechanisms to implement of sustainable development concept; creating green workplaces.

The National Bank's decisions should be based on the following priority areas for structural reform: promoting innovation, improving infrastructure, developing competition and favorable conditions, improving and strengthening the financial system, promoting tax reform, enhancing environmental sustainability, promoting inclusive growth, promoting trade development and promoting trade, promoting labor market reform, educational attainment and skills. Big data issues are becoming increasingly important as an effective tool for efficient reallocation of resources.

In this context he uses of big data allows the company to gain tangible competitive advantages. Big data technologies can be useful for solving the following tasks: forecasting the current situation in the markets of ecoproducts and eco-services, marketing and optimization of sales of eco-products, decision-making and management in the environmental management system, improving productivity and creating green jobs, efficient logistics, monitoring of assets nature conservation purpose.

Green business development requires considerable cost and additional government support. That is why the tools of running date, analysis of big data sets, interpretation of trends and specifics of development, accent on popular industries are becoming very popular. The use of running dates allows to carry out a full analysis of the project implementation and to create the structure of investment portfolio for its implementation. This is where the help of Fintech tools come into play, which greatly simplifies financial transactions and interaction between companies in different countries. Financial technologies, websites and applications help minimize green business costs.

Today, FinTech in the green business is used for cash transactions, conclusion of insurance contracts, remote asset management of environmental purposes, storing funds in electronic wallets, paying for online services, obtaining loans for environmental projects without the help of banks.

The use of Fintech allows integrating green economy sectors with the financial sector. The development of technology will simplify many processes. For example, in agriculture, you can now use sensors or drones that record the state of crops and their growth dynamics, taking into account various factors. By collecting and analyzing these data, the bank receives a risk assessment for lending to agriculture, based on real statistics.

Development of energy complex, first of all, depends on GDP growth and development level of economy in general. It is necessary to consider approaches to forecast production and consumption of energy resources, which are presented by the energetic strategy. Though, such renewables as solar and wind power is developing rapidly in Ukraine, it is not enough for structural changes in energetic balance. There will remain constant trends towards using coal as the main energy resource in the country for another 20-30 years. This goes to prove 
priority use of non-renewable natural sources. However, all economically developed countries and other countries in the world switch to alternative energy sources.

Along with development of alternative energy sources and reducing consumption of natural resources, there is also a problem of waste utilization as an integral part of green energetics process. Greening of Ukrainian economy may cardinally change image of Ukraine among other countries in the world and lead to further improvement of investment climate.

Use of effective methods and tools for implementing provisions of conception of greening economy will reduce amount of non-renewable natural resources, reduce costs for installation and use of alternative energy sources, ensure ecosystem restoration and ecological and economic growth of Ukraine in general.

\section{Conclusions}

There is a demand to develop effective measures for ecologization of all spheres of economic activity under current complex economic and ecological conditions. Implementation of principles of ecological economics becomes possible with using methods and mechanisms for its implementation, such as: price formation taking into account environmental factors; assessment of natural resources and loss of its overexploitation in money terms; ecological tax reform by increasing value of ecological taxes and reducing rates of other taxes and fees; target state policy of procurement on production and sales of ecologically clean products; increase state investments in development of renewable energy sources; construct treatment engineering and others. The existence of a large database of environmental processes in enterprises is often difficult to analyze. Therefore, there is a need to use financial technologies and methods to analyze large amounts of data, such as running date analysis.

Currently traditional data analysis is predominantly used for economic analysis in public and private sector. There is considerable potential for improved strategic planning at green enterprises, better understanding of the economic and ecological activity which is now not accounted for during traditional data analysis (shadow economy), shift to forward-looking approach to data analysis in the sphere of green business and green innovations. We detected several issues when it comes to implementation of the big data analysis in public and private sectors:

- modernization of the equipment, the choice of software compatible with existing IT-infrastructure would require significant investments as well as additional training for the staff;

- in order to facilitate implementation of the big data management in the sphere of green business it is necessary to create automated system of data sharing between public and private sectors;

- digitalization is largely dependent on support from donors (countries and organizations), this situation is unsustainable in the long-run;

- there is lack of skillful employees in area of green economy analysis;
- complexity of implementation of Fin Tech and big data analysis in the developing countries.

Review of the current state of the big data analysis have made it evident that there is growing understanding of possible benefits of use of this techniques in public sector, namely in decision making process, supervision, anti-corruption measure, fraud prevention. Eventually, existing issues that halt development of the big data analysis initiatives could be resolved and this might lead to exponential growth of such initiatives in public sector. Under these circumstances it is reasonable to combine economic and environmental component of social and economic reforms at national, regional and local levels and to consider it as a complex when looking for ways out of tough economic situation. Considering these, strategic model of sustainable development should be based on the following principles of green economy:

- assessment and priority to provide natural services at national and international levels;

- ensure employment of population by creating green workplaces and development effective and appropriate environmental policy;

- use of market mechanisms to implement concept of sustainable development.

Therefore, it is necessary to improve theoretical, methodological, organizational and practical principles of green business functioning. Contribution to the transition of the industry to the principles of the resource effective and clean production is the key task for the implementation of the stable development concept in different countries. Application of FinTech, methods of processing large data sets and tools for implementing the principles of greening the economy will enable to increase the investment attractiveness of green business and will simplify the interaction between the state and enterprises. This will facilitate development of environmental business, implementing model of environmentally-clean manufacturing at enterprises of green business, preserving and efficient use of resources, reducing destructive effects of industrial and human activities on environment, consolidation of researches on adaptation of green technologies.

\section{References}

1. Renewables 2017: Global Status Report (REN21 Secretariat, Paris, 2017), https://www.ren21.net/wpcontent/uploads/2019/05/GSR2017_Full-

Report_English.pdf. Accessed 10 Fëb 2020

2. Renewables 2019: Global Status Report (REN21 Secretariat, Paris, 2019, https://www.ren21.net/wpcontent/uploads/2019/05/gsr_2019_full_report_en.p df. Accessed 10 Feb 2020

3. D. Boyd, K. Crawford, Critical questions for big data: Provocations for a cultural, technological, and scholarly phenomenon. Inform., commun. \& soc. 15 , 662-679 (2012)

4. K. Crawford, The hidden biases in big data (Harvard Business Review, 2013), https://hbr.org/2013/04/thehidden-biases-in-big-data. Accessed 10 Feb 2020 
5. K. Desouza, B. Jacob, Big data in the public sector: lessons for practitioners and scholars. Admin. \& Soc. 49, 1043-1064 (2017)

6. G. Kim, S. Trimi, J. Chung, Big-data applications in the government sector. Commun. of the ACM 57, 78-85 (2014)

7. J. Mervis, Agencies rally to tackle big data. Sc. 336, 22 (2012)

8. I. Rakov, Mechanisms for financing green projects: country experience. Cur. iss. of econ. and law. 2, 6782 (2017)

9. H. Akaike, A new look at the statistical model identification. IEEE transact. on autom. cont. 6, 716723 (1974)

10. G. Schwarz, Estimating the dimension of a model. The ann. of stat. 2, 461-464 (1978)

11. M. Cox, D. Ellsworth, Managing big data for scientific visualization, in ACM Siggraph 97, pp. 2138

12. C. Lynch. Big data: How do your data grow. Nat. 455, 28 (2008)

13. J. Manyika, M. Chui, B. Brown, J.Bughin, R. Dobbs, C. Roxburgh, A. Byers, Big data: The next frontier for innovation, competition, and productivity (McKinsey Global Institute, New York, 2011)

14. J. Hill, in Fintech and the Remaking of Financial Institutions, 1st edn. (Springer, New York, 2018)

15. I. Lee, Y. Shin, Fintech: Ecosystem, business models, investment decisions, and challenges. Bus. hor. 61, 35-46 (2017)

16. U. Sivarajah, M. Kamal, Z. Irani, V. Weerakkody, Critical analysis of Big Data challenges and analytical methods. Journ. of Bus. Res. 70, 263-286 (2017)

17. J. Begenau, M. Farboodi, L. Veldkamp. Big data in finance and the growth of large firms. Journ. of Mon. Econ. 97, 71-87 (2018) 